\title{
POLÍTICAS PÚBLICAS E DESENVOLVIMENTO
}

\author{
Public Policies and Development
}

Políticas Públicas y Desarrollo

Mônica Aparecida da Rocha Silva ${ }^{{ }_{1}}$, Ana Lúcia Medeiros ${ }^{1}$

${ }^{1}$ Programa de Pós-graduação em Desenvolvimento Regional, Universidade Federal do Tocantins, Palmas,

Tocantins, Brasil.

*Correspondência: Programa de Pós-graduação em Desenvolvimento Regional (PPGDR), Universidade Federal do Tocantins, Av. NS 15, 109 Norte, Palmas, Tocantins, Brasil.CEP:77.010-090.e-mail pgdra@uft.edu.br

\section{EDITORIAL}

A proposta do Dossiê Políticas públicas e Desenvolvimento consiste na divulgação de trabalhos científicos que tratam de uma perspectiva de desenvolvimento associada à redução das desigualdades sociais e regionais. Essa concepção tem se tornado um desafio para gestores públicos e um importante campo de estudo para diferentes áreas do conhecimento. Trata-se de um processo complexo que gera reflexões, discussões acerca das suas problemáticas e a apresentação de prováveis caminhos a serem adotados no sentido de estimular atores sociais, públicos e privados na busca de soluções para as demandas da sociedade.

Os temas que contemplam este Dossiê foram definidos com vistas a convidar os (as) pesquisadores (as) para refletirem sobre as políticas públicas e o desenvolvimento, especialmente do estado do Tocantins. O presente Dossiê temático é constituído de um conjunto de nove artigos que, de modo distinto, desenvolvem a reflexão teórica e metodológica sobre este tema.

Abrindo os artigos do Dossiê temos o texto dos autores Diego Neves de Sousa, Michele Silva Costa Sousa e Waldecy Rodrigues, intitulado "Análise das políticas públicas para a agricultura familiar: o que tem feito o governo do Tocantins?”. Os autores discutem as políticas públicas para a agricultura familiar, criadas pelo governo do Tocantins, com base na percepção de 80 mediadores sociais. Conclui-se que a maioria das políticas conhecidas como "estaduais" pelos mediadores, são fomentadas por recursos federais, mas executadas por órgãos do estado, como é o caso das políticas públicas: Compra Direta e Terra Forte.

$\mathrm{Na}$ sequência, temos o artigo "Políticas Públicas de Cultura: análise do Plano Estadual de
Cultura do Tocantins à luz do modelo neoinstitucionalista", de Poliana Macedo de Sousa e José Rogério Lopes. Neste trabalho, os autores analisam o Plano Estadual de Cultura do Tocantins (PEC/TO) e as ações desenvolvidas após a implantação dessa política pública. Apresentam, também, um breve histórico das políticas públicas para cultura no Brasil e no Tocantins. E, sob a perspectiva da teoria neoinstitucionalista, os autores apontam que a criação, a permanência ou a mudança de instituições não é resultado de um processo funcional de busca de maior eficiência, mas sim de uma busca por maior legitimidade.

Já os autores Reinaldo Pereira de Brito Costa, Nilton Marques de Oliveira e Fernando Silva Lima, no artigo "Análise da situação financeira do estado do Tocantins por categoria econômica", destacam que $92 \%$ dos gastos do estado se concentram na categoria econômica despesas correntes, e, 60\%, destas, foram empenhadas com Pessoal e Encargo Social, mas dentro dos limites estabelecidos pela LRF. Conclui-se que em todos os períodos analisados, o estado do Tocantins obteve superávit orçamentário, evidenciando que as receitas arrecadadas são superiores ao valor das despesas empenhadas nos exercícios e demonstrando equilíbrio entre os referidos valores.

$\mathrm{O}$ artigo "Registros de patentes e suas relações com as cadeias produtivas locais: a experiência da Universidade Federal do Tocantins", elaborado pelos autores Pedro Eliagi de Oliveira, Ana Lúcia de Medeiros e Kleber Abreu Sousa, mostra as experiências da UFT na produção de patentes e apresenta que esta produção científica e tecnológica é orientada para soluções que podem desenvolver as cadeias produtivas do estado do Tocantins. 
Na sequência, temos o artigo "Qualidade de Vida e Trabalho docente no Ensino Superior: uma revisão da literatura", dos autores Jeann Bruno Ferreira da Silva; Mônica Aparecida da Rocha Silva e Waldecy Rodrigues. Neste trabalho, analisouse a produção científica acerca da Qualidade de Vida (QV) de Docentes do Ensino Superior. Com base na abordagem cienciométrica, para análise e tratamento dos dados, averiguou-se que a maioria dos artigos (45\%) foram publicados no ano de 2015, 36\% foram publicados na região Sul, dos autores principais $54 \%$ possuem titulação de doutor e as classificações dos periódicos de maior prevalência foram Qualis A1 e A2. Este estudo evidenciou a necessidade de se realizar mais pesquisas sobre o tema em questão, bem como conferir maior relevância ao fenômeno Qualidade de Vida dos docentes do magistério superior e dar maior visibilidade sobre o trabalho destes profissionais.

Por sua vez, o artigo "Conselho Municipal de Educação de Palmas: criação, composição, funções e ações", de autoria do Jorcelyo Alencar Lima, Jacira Brito Tavares e Jacinta Brito Tavares, evidencia que o Conselho cumpre as funções fundantes, como normativa, consultiva, fiscalizadora, propositiva e de controle social, em detrimento da função mobilizadora, o que compromete o diálogo e a coparticipação da comunidade.

Os autores Edna Primo da Silva e Josivaldo Alves da Silva, no artigo "Gestão de projetos sociais: uma análise do modelo de gerenciamento adotado por uma secretaria municipal de Dianópolis/TO, a partir do guia PMBOK”, apontam que a Secretaria de Esporte e Juventude do município pesquisado não utiliza um guia de gerenciamento de projetos para padronizar os processos, estabelecer diretrizes claras de gestão e não dispõe de profissionais capacitados para atuar no gerenciamento destes projetos.

Já o artigo "Ocupação espacial migração $e$ mobilidade urbana: a construção econômica de Imperatriz-MA", de autoria de Jorcelyo Alencar Lima e Elisangela de Andrade Borges Alencar, discute questões de mobilidade urbana, utilizando como exemplo, a construção econômica do município de Imperatriz no estado do Maranhão, originada por fluxos migratórios a partir da segunda metade do século $\mathrm{XX}$.

Concluindo este Dossiê da Revista Desafios, temos um artigo que não se caracteriza por ser um estudo ou pesquisa sobre o estado do Tocantins ou mesmo o Brasil, mas que possui convergência com o tema Políticas Públicas e Desenvolvimento, em especial sobre a questão do desmatamento no estado e no nosso país. Sendo assim, no artigo "Análise sistêmica da legislação ambiental e das políticas públicas contra o desmatamento no Haiti", de autoria de Jhon-Kelly Monacé, Mônica Aparecida da Rocha Silva e Waldecy Rodrigues, os autores apresentam um diagnóstico parcial das políticas públicas haitianas contra o desmatamento à luz da análise sistêmica. Argumenta-se que, a ausência de políticas públicas voltadas para o setor energético e a falta de políticas públicas ambientais eficientes criaram condições nas quais a população foi motivada a usar os recursos florestais para satisfazer suas necessidades energéticas.

Boa leitura! 